\title{
Readmission of Patients with Acute Coronary Syndrome and Determinants
}

\author{
Larissa Marina Santana Mendonça de Oliveira, ${ }^{1 \oplus}$ Ingrid Maria Novais Barros de Carvalho Costa, ${ }^{1,2}$ Danielle \\ Góes da Silva, ${ }^{3}$ José Rodrigo Santos Santos Silva, ${ }^{4}$ José Augusto Soares Barreto-Filho, 1,5,6 Marcos Antônio \\ Almeida-Santos, ${ }^{7}$ Joselina Luzia Meneses Oliveira, ${ }^{1,5}$ Mirella Dornelas Batalha Moreira Buarque, ${ }^{8,9}$ Diva Aliete dos \\ Santos Vieira, ${ }^{10}$ Antônio Carlos Sobral Sousa ${ }^{1,5,6}$ \\ Universidade Federal de Sergipe - Departamento de Pós-Graduação em Ciências da Saúde, ${ }^{1}$ São Cristovão, SE - Brazil \\ Instituto Federal de Educação Ciência e Tecnologia de Sergipe, ${ }^{2}$ São Cristovão, SE - Brazil \\ Universidade Federal de Sergipe - Departamento de Nutrição, ${ }^{3}$ São Cristovão, SE - Brazil \\ Universidade Federal de Sergipe - Departamento de Estatística, ${ }^{4}$ São Cristovão, SE - Brazil \\ Universidade Federal de Sergipe - Departamento de Medicina, ${ }^{5}$ São Cristovão, SE - Brazil \\ Fundação São Lucas - Centro de Ensino e Pesquisa, ${ }^{6}$ Aracaju, SE - Brazil \\ Programa de Pós-graduação em Saúde e Ambiente da Universidade Tiradentes, ${ }^{7}$ Aracaju, SE - Brazil \\ Hospital do Coração, ${ }^{8}$ Aracaju, SE - Brazil \\ Fundação de Beneficência do Hospital Cirurgia, ${ }^{9}$ Aracaju, SE - Brazil \\ Universidade Federal de Sergipe - Departamento de Nutrição, ${ }^{10}$ Lagarto, SE - Brazil
}

\section{Abstract}

Background: Acute coronary syndrome (ACS) is responsible for high rates of hospital admission and readmission, which are associated with increased costs for the patient and the health system, and increased in-hospital mortality rates.

Objective: To evaluate readmission in patients with ACS and its determinants.

Methods: This was a retrospective cohort study of adult and elderly patients with ACS, readmitted to public and private referral cardiology hospitals within one year after the first hospitalization for ACS. The occurrence of readmissions, the time elapsed from the first to the second admission, and the use of medications at admission were collected from the medical records. Associations between categorical variables were evaluated by the chi-square test or the Fisher's exact test. Multiple logistic regression was used to evaluate predictors for readmissions. A $p<0.05$ was set as statistically significant.

Results: Readmission rate was $21.5 \%(n=115)$ and mean time between admissions was $122.7 \pm 112.1$ days. The patients were mostly men (64.0\%), mean age of $63.15 \pm 12.3$ years. Among readmitted patients, $7 \%$ had a prognosis of "death", and $68.7 \%$ were readmitted more than once within a one-year period. The main reasons of readmission were cardiovascular diseases including ACS. Private health care and the diagnosis of congestive heart failure were associated with multiple logistic regression.

Conclusion: ACS was the main cause of readmission, with higher prevalence among users of supplemental health care. Readmissions were associated with previous diagnosis of congestive heart failure and the type of health care provided. (Arq Bras Cardiol. 2019; 113(1):42-49)

Keywords: Acute Coronary Syndrome; Hospitalization/economy; Patient Readmission/economy; Heart Failure; Delivery of Health Care/economy; Hospital Mortality; Socioeconomic Factors; Drug Therapy/economia.

\section{Introduction}

During the last years, there has been increasing rates of hospital admission and readmission for ischemic heart diseases, including acute coronary syndrome (ACS). ${ }^{1}$ Hospital readmissions account for a significant increase in costs for the patient and public and private health system, and in

Mailing Address: Larissa Marina Santana Mendonça de Oliveira • Universidade Federal de Sergipe - R. Cláudio Batista, s/n - Palestina, Postal Code 49060-108, Aracaju, SE - Brasil, Aracaju, SE - Brazil

E-mail: nutrilarissamarina@gmail.com

Manuscript received August 09, 2018, revised manuscript October 23, 2018, accepted November 01, 2018

DOI: $10.5935 / a b c .20190104$ hospital mortality. The risk of death in readmitted patients is greater when readmissions occur for cardiac causes. ${ }^{2-4}$

After an ACS event, hospital readmissions may be associated with different cardiac conditions, including myocardial ischemia, arterial fibrillation and uncontrolled hypertension, and also non-cardiac conditions such as poor treatment adherence, alcohol consumption, psychological factors, socioeconomical factors and health system issues. ${ }^{5-7}$ Besides, hospital readmissions are correlated with the quality of the health care provided and management of comorbidities during hospitalization, and hence may be used as quality indicators of the healthcare services. ${ }^{8,9}$ The type of health care system can also influence readmission rates, as it reflects different levels of access to health care and inequality between individuals. ${ }^{8}$ 


\section{Original Article}

Therefore, the present study aimed to evaluate readmission rates after an ACS event among users of a public, supplemental health care system in the state of Sergipe, Brazil, and to evaluate the association between readmission rate and socioeconomic determinants of lifestyle and clinical outcomes.

\section{Methods}

\section{Study design}

This was a retrospective cohort study of patients with ACS, conducted between August 2017 and April 2018. A total of 581 patients was selected during the first admission (October 2013-September 2015) to one of the four referral hospitals in the city of Aracaju, Brazil. Three of these institutions provided private health services and one of them provided public services. All participants were evaluated at three time points throughout the study: at hospital admission, and 30 days and 180 days after the ACS event. ${ }^{4}$

Clinical diagnosis of ACS at admission and the type of ACS - acute ischemia, acute myocardial infarction with ST-segment elevation (STEMI), and acute myocardial infarction without ST-segment elevation (NSTEMI) - were collected from medical records. These diagnoses were made based on physician's interpretation of symptoms (consistent with acute ischemia in the 24 hours prior to admission) and/or on elevation of biomarkers of cardiac ischemia, confirmed by electrocardiography, Doppler echocardiography or coronary cineangiography.

Once personal data (name, date of birth, date of hospital admission) of patients were obtained, the medical records were searched for the occurrence of readmissions within one year after the first admission for ASC.

\section{Study sample}

One-year readmission after first hospitalization for ACS was investigated in a cohort of 581 patients with ACS (Figure 1).

\section{Inclusion criteria}

All patients admitted for ACS in cardiology referral hospitals in Aracaju, Sergipe, Brazil, identified at baseline of the study were included.

\section{Exclusion criteria}

Patients who died during or after discharge of the first hospitalization, patients who were not readmitted after discharge of the first admission, and those who were presented readmission with less than 24 hours of hospital stay.

\section{Outcome measures}

\section{Socioeconomic status}

Patients' personal data were retrieved from the database of first admitted ACS patients during the period from October 2013 to September 2015. ${ }^{4}$ A semi-structured questionnaire was used at the time of admission for ACS. Data of age (adults and elderly patients), sex (female and male), self-referred race (white, pardo, black), educational attainment (more or less 9 years of schooling), per capita income (less than 1 salary/person, 1-3 salaries/person, 3-5 salaries/person and more than 5 salaries/ person), type of health care (public or private), life habits - alcohol consumption and smoking, reported by the patient or caregiver, and physical activity (classified by the international physical activity questionnaire, IPAQ) - nutritional status according to the body mass index (BMI) and waist circumference (WC). BMI was classified into low weight, normal weight and overweight, according to the World Health Organization (WHO) ${ }^{10}$ cut-off points (for adults) and the Pan American Health Organization $(\mathrm{PAHO})^{11}$ cut-off points (for older patients). A WC $<80 \mathrm{~cm}$ for women and $<94 \mathrm{~cm}$ for men was considered normal. ${ }^{10}$

\section{Hospital readmission}

Occurrence of readmissions within one year after discharge was searched in the medical records of four cardiology referral hospitals. Data regarding the cause and date of readmissions and use of medications at the time of readmission were collected. All this information was transferred into a structured questionnaire.

Hospital admissions were categorized according to the primary diagnosis and the reason of admission - ACS, cardiovascular and noncardiovascular causes.

\section{Drug therapy}

After 30 and 180 days after discharge, the use, or not, of the following drugs was assessed: antiplatelet agents, statins,

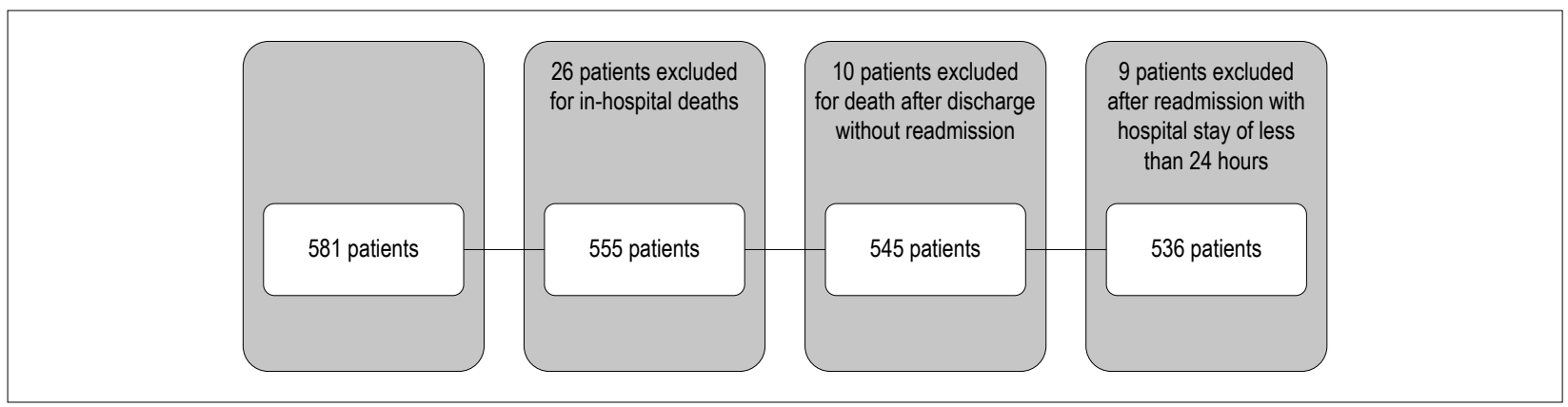

Figure 1 - Flow chart of the occurrence of readmission within one year after the first admission in patients with acute coronary syndrome. 
beta blockers, angiotensin-converting enzyme inhibitors (ACEI), and angiotensin receptor blockers (ARBs). The use of these medications at home was also evaluated at readmission (collected from the medical records).

\section{Physical activity}

The practice of physical activity was evaluated using the short version of the IPAQ. ${ }^{12,13}$ This instrument classifies the patient into four categories, based on the intensity levels of physical activity: very active, active, insufficiently active and inactive. In our study, "very active" and "active" individuals according to the IPAQ were considered "active", and those classified as "insufficiently active" and "inactive" in the IPAQ were considered "inactive". The level of physical activity at hospital admission, and 30 days and 180 days after discharge was assessed by telephone.

\section{Clinical features}

We evaluated the type of ACS at first admission, and the presence of previous systemic arterial hypertension $(\mathrm{SAH})$, diabetes mellitus (DM), dyslipidemias, coronary artery disease (CAD), congestive heart failure, angina, AMI, angioplasty, myocardial revascularization and chronic kidney disease. All variables were categorized into present or absent (yes or no).

\section{Statistical analysis}

Categorical variables were expressed as absolute and relative frequency, and distribution of quantitative variables was tested for normality using the Kolmogorov-Smirnov test. Variables that met the assumption of normality were presented as mean and standard deviation. Associations between categorical variables were assessed using the chi-square test or the Fisher's exact test, as appropriate. A p $<0.05$ was set as statistically significant; all variables with $p<0.20$ after association test and those that were risk factors for cardiovascular diseases were subjected to multiple logistic regression analysis.

Fourteen variables- sex, type of health care, race, age, hypertension, dyslipidemia, DM, congestive heart failure, use of statins on day 180, educational attainment, smoking, alcohol consumption, type of ACS - were selected as independent variables in the regression model, and readmission as dependent variable. The odds ratio (OR) and 95\% confidence interval was used in the model. The Hosmer-Lemeshow goodness of fit test was used to evaluate the fitness of the model.

All analyses were performed using the R software, version 3.4.0 (The R Core Team, 2016). ${ }^{14}$

\section{Results}

A total of 536 patients were considered eligible for the study. Mean age was $63.15 \pm 12.26$ years, and most of the were men $(64.0 \%)$. One hundred fifteen readmitted patients were identified (21.5\%). Readmissions occurred $122.74 \pm 112.14$ days after discharge from the first hospitalization. Among readmitted patients, $7 \%$ had the prognosis of "death", and $68.7 \%$ were readmitted more than once within a one-year period.

Regarding the reasons of hospital readmissions, $42.6 \%$ were ACS, 20.9\% other cardiovascular causes (pulmonary hypertension, peripheral obstructive disease, second-degree atrioventricular block, and mitral insufficiency) and 36.52\% other noncardiovascular causes (malnutrition, respiratory insufficiency, kidney disease, DM and complications, unspecified disorder of vestibular function, diverticulitis, hernioplasty, trauma and hyponatremia).

Table 1 presents the association of readmission with socioeconomic variables with the type of health care provided, nutritional status and life style. White patients, patients with higher educational attainment, those with higher family income and users of private health care services showed higher readmission rates.

Regarding clinical conditions associated with readmission (Table 2), readmission rates were higher in patients with STEMI, dyslipidemias, chronic kidney disease, congestive heart failure, angina, AMI, and previous angioplasty.

With respect to the use of medications after hospital discharge (Table 3), only absence of statin 180 days after the ACS event was associated with hospital readmission.

Factors associated with readmission were subjected to multiple logistic regression analysis (Table 4). Type of health care and congestive heart failure showed statistical significance. Users of private health care services had higher odds of rehospitalization than those attending public health clinics. However, patients with previous congestive heart failure had 1.81 times greater odds of readmissions.

\section{Discussion}

The readmission rate of $21.46 \%$ found in the present study was similar to that $\left(24.5 \%\right.$ ) reported in the study by Dreyer et al., ${ }^{15}$ who evaluated the rate of readmissions in 3,536 patients within one year after AMI in the USA. A study conducted in Canada with 3,411 patients of both sexes reported a higher readmission rate $(61.7 \%)$ in one year after first hospitalization for ACS. ${ }^{7}$

Rehospitalization rates in our study were also lower than those reported by Ricci et al.(47.9\%), ${ }^{8}$ evaluating 30-day readmission in a complex care hospital. Sangu et al. ${ }^{16}$ believe that readmission rates can be influenced by the time period of evaluation following discharge. Readmission rates can also be affected by geographic factors in a population. ${ }^{17}$

Readmission rate is also a predictor of the performance of hospital activities and the occurrence of complications after discharge, ${ }^{18}$ which can reflect the accessibility to primary health care services. Self-referral to hospitals may be explained by a difficult access to primary care services, and the idea of a treatment focused on acute rather than chronic care, which raises self-referral to complex care hospitals. ${ }^{19,20}$

Readmission rates, however, are not always associated with the access to health care centers and quality of care provided. The rates may be associated with complexity of disease and patients' individual features, including socioeconomic status and disease severity. On the other hand, planned readmissions have been associated with the quality of hospital care. ${ }^{21,22}$ 


\section{Original Article}

Table 1 - Socioeconomic data, nutritional status, lifestyle habits, and type of health care provided associated with readmission in patients with acute coronary syndrome in Aracaju, Brazil, 2017

\begin{tabular}{|c|c|c|c|}
\hline \multirow{2}{*}{ Variable (\%) } & \multicolumn{2}{|c|}{ Readmission } & \multirow{2}{*}{ p value } \\
\hline & Yes & No & \\
\hline \multicolumn{4}{|l|}{ Socioeconomic variables } \\
\hline \multicolumn{4}{|l|}{ Sex } \\
\hline Female & $49(25.39 \%)$ & $144(74.61 \%)$ & \multirow[t]{2}{*}{0.1201} \\
\hline Male & $66(19.24 \%)$ & $277(80.76 \%)$ & \\
\hline \multicolumn{4}{|l|}{ Race } \\
\hline White & $55(29.73 \%)$ & $130(70.27 \%)$ & \multirow[t]{2}{*}{0.0008} \\
\hline Black/pardo & $54(16.67 \%)$ & $270(83.33 \%)$ & \\
\hline \multicolumn{4}{|l|}{ Educational attainment } \\
\hline$<9$ years & $44(16.18 \%)$ & $228(83.82 \%)$ & \multirow[t]{2}{*}{0.0035} \\
\hline$\geq 9$ years & $71(26.89 \%)$ & $193(73.11 \%)$ & \\
\hline \multicolumn{4}{|l|}{ Family income (per capita) } \\
\hline$\leq 1$ salary/person & $12(12.63 \%)$ & $83(87.37 \%)$ & \multirow{4}{*}{0.0022} \\
\hline$>1$ salary and $\leq 3$ salaries/ person & $20(14.93 \%)$ & $114(85.07 \%)$ & \\
\hline$>3$ salaries e $\leq 5$ salaries/ person & $29(23.97 \%)$ & $92(76.03 \%)$ & \\
\hline$>5$ salaries/ person & $53(29.12 \%)$ & $129(70.88 \%)$ & \\
\hline \multicolumn{4}{|l|}{ Age group } \\
\hline Adults & $35(16.99 \%)$ & $171(83.01 \%)$ & \multirow[t]{2}{*}{0.0599} \\
\hline Elderly & $80(24.24 \%)$ & $250(75.76 \%)$ & \\
\hline \multicolumn{4}{|l|}{ Nutritional status } \\
\hline \multicolumn{4}{|l|}{ BMI } \\
\hline Low weight & $6(18.18 \%)$ & $27(81.82 \%)$ & \multirow{3}{*}{0.8271} \\
\hline Normal weight & $48(22.43 \%)$ & $166(77.57 \%)$ & \\
\hline Overweight & $60(20.91 \%)$ & $227(79.09 \%)$ & \\
\hline \multicolumn{4}{|l|}{ Abdominal circumference } \\
\hline Inadequate & $83(20.75 \%)$ & $317(79.25 \%)$ & \multirow{2}{*}{1.0000} \\
\hline Adequate & $27(21.09 \%)$ & $101(78.91 \%)$ & \\
\hline \multicolumn{4}{|l|}{ Lifestyle habits } \\
\hline \multicolumn{4}{|l|}{ Physical activity at admission } \\
\hline Inactive & $66(23.08 \%)$ & $220(76.92 \%)$ & \multirow{2}{*}{0.3828} \\
\hline Active & $49(19.6 \%)$ & $201(80.4 \%)$ & \\
\hline \multicolumn{4}{|l|}{ Physical activity 30 days after admission } \\
\hline Inactive & $89(20.37 \%)$ & $348(79.63 \%)$ & \multirow{2}{*}{0.6298} \\
\hline Active & $11(16.92 \%)$ & $54(83.08 \%)$ & \\
\hline Physical activity 180 days after admis & & & \\
\hline Inactive & $62(22.55 \%)$ & $213(77.45 \%)$ & กองคอ \\
\hline Active & $36(17.56 \%)$ & $169(82.44 \%)$ & $0.2 \angle 03$ \\
\hline Alcohol consumption & & & \\
\hline Yes & $15(22.06 \%)$ & $53(77.94 \%)$ & 1.0000 \\
\hline No & $100(21.37 \%)$ & $368(78.63 \%)$ & \\
\hline Smoking & & & \\
\hline Yes & $17(18.89 \%)$ & $73(81.11 \%)$ & 0.6105 \\
\hline No & $98(21.97 \%)$ & $348(78.03 \%)$ & \\
\hline Type of health care & & & \\
\hline Private & $89(29.47 \%)$ & $213(70.53 \%)$ & $<0.0001$ \\
\hline Public & $26(11.11 \%)$ & $208(88.89 \%)$ & \\
\hline
\end{tabular}

${ }^{*}$ Chi-square test 
Table 2 - Clinical conditions associated with readmissions in patients with acute coronary syndrome in Aracaju, Brazil, 2017

\begin{tabular}{|c|c|c|c|}
\hline \multirow{2}{*}{ Variable } & \multicolumn{2}{|c|}{ Readmission } & \multirow{2}{*}{$p$ value ${ }^{*}$} \\
\hline & Yes & No & \\
\hline \multicolumn{4}{|l|}{ Type of ACS } \\
\hline Unstable angina & $20(20.83 \%)$ & $76(79.17 \%)$ & \\
\hline NSTEMI & $56(27.45 \%)$ & $148(72.55 \%)$ & 0.0205 \\
\hline STEMI & $39(16.53 \%)$ & $197(83.47 \%)$ & \\
\hline Arterial hypertension & $97(22.99 \%)$ & $325(77.01 \%)$ & 0.1255 \\
\hline Dyslipidemias & $81(27.93 \%)$ & $209(72.07 \%)$ & 0.0001 \\
\hline Diabetes mellitus & $48(25.81 \%)$ & $138(74.19 \%)$ & 0.0933 \\
\hline Previous CAD & $59(30.73 \%)$ & $133(69.27 \%)$ & 0.0001 \\
\hline Congestive heart failure & $39(31.45 \%)$ & $85(68.55 \%)$ & 0.0030 \\
\hline Previous AMI & $58(30.53 \%)$ & $132(69.47 \%)$ & 0.0002 \\
\hline Previous angioplasty & $31(32.29 \%)$ & $65(67.71 \%)$ & 0.0066 \\
\hline Previous myocardial revascularization & $12(31.58 \%)$ & $26(68.42 \%)$ & 0.1700 \\
\hline Previous chronic kidney disease & $18(51.43 \%)$ & $17(48.57 \%)$ & $<0.0001$ \\
\hline
\end{tabular}

*ACS: acute coronary syndrome; NSTEMI: acute myocardial infarction without ST-segment elevation (NSTEMI); STEMI: acute myocardial infarction with ST-segment elevation (STEMI); AMI: acute myocardial infarction; CAD: coronary artery disease; Chi-square test.

Table 3 - Drug therapy associated with readmissions in patients with acute coronary syndrome in Aracaju, Brazil, 2017

\begin{tabular}{|c|c|c|c|}
\hline \multirow{2}{*}{ Variable } & \multicolumn{2}{|c|}{ Readmission } & \multirow{2}{*}{$p$ value* } \\
\hline & Yes & No & \\
\hline Without ASA for 30 days & $3(15.8 \%)$ & $16(84.2 \%)$ & 1.0000 \\
\hline Without antiplatelet agents for 30 days & $9(30.0 \%)$ & $21(70 \%)$ & 0.2111 \\
\hline Without statin for 30 days & $6(11.5 \%)$ & $46(88.5 \%)$ & 0.2037 \\
\hline Without $\beta$-blockers for 30 days & $12(35.3 \%)$ & $22(64.7 \%)$ & 0.0507 \\
\hline Without ACEI and/or ARBs for 30 days & $6(15.0 \%)$ & $34(85.0 \%)$ & 0.4259 \\
\hline Without ASA for 180 days & $5(14.3 \%)$ & $30(85.7 \%)$ & 0.4566 \\
\hline Without antiplatelet agents for 180 days & $9(16.4 \%)$ & $46(83.6 \%)$ & 0.5640 \\
\hline Without statin for 180 days & $8(10.3 \%)$ & $70(89.7 \%)$ & 0.0293 \\
\hline Without $\beta$-blockers for 180 days & $12(24.5 \%)$ & $37(75.5 \%)$ & 0.6863 \\
\hline
\end{tabular}

* acetylsalicylic acid (ASA); ACEl: angiotensin-converting enzyme inhibitors; ARBs: angiotensin receptor blockers; chi-square test or Fisher's exact test

The presence of other risk factors, particularly concomitant ones, increases the odds of readmission. ${ }^{23}$ The occurrence of comorbidities associated with ACS affects disease severity, and increases the need for invasive interventions. A study conducted by Belitardo \& Ayoub, ${ }^{1}$ that evaluated readmission in elderly patients, reported that $\mathrm{SAH}$, sedentary lifestyle, dyslipidemia, DM, stress, smoking and obesity increased the odds of requiring invasive procedures and readmissions.

Patient destination after discharge, which is related to disease severity, is also associated with 30-day readmission in patients with congestive heart failure, as discussed in the study by Mirkin et al. ${ }^{24}$ Patients had different destinations after discharge, and those requiring specialized support services had higher readmission rates.

The diversity of causes of readmission reinforces the importance of the access to regional health services and the degree of coverage of health services to reduce risk factors and complications that may affect readmission outcomes. ${ }^{25}$

Therefore, strategies aimed at reducing the occurrence of readmission should include planning of discharge, promotion of health education of patients and family members, scheduling of patients' follow-up before and after discharge, appropriate use of medications, effective communication 


\section{Original Article}

Table 4 - Multiple logistic regression of variables in patients with acute coronary syndrome in Aracaju, Brazil, 2017

\begin{tabular}{llc}
\hline Variables & OR $(95 \% \mathrm{Cl})$ & p value \\
\hline Male sex & $0.78(0.45 ; 1.38)$ & 0.396 \\
Public health care & $0.46(0.21 ; 0.98)$ & 0.048 \\
Elderly patients & $1.11(0.63 ; 1.99)$ & 0.718 \\
Black/pardo race & $0.58(0.34 ; 1.00)$ & 0.050 \\
Hypertension & $1.72(0.85 ; 3.73)$ & 0.149 \\
Dyslipidemia & $1.69(0.96 ; 3.04)$ & 0.073 \\
Diabetes mellitus & $0.92(0.53 ; 1.56)$ & 0.749 \\
Congestive heart failure & $1.81(1.01 ; 3.21)$ & 0.042 \\
Without statin for 180 days & $0.76(0.31 ; 1.70)$ & 0.526 \\
High school/higher education & $1.56(0.87 ; 2.85)$ & 0.140 \\
Smoking & $1.43(0.65 ; 2.99)$ & 0.356 \\
Alcohol consumption & $1.93(0.86 ; 4.22)$ & 0.102 \\
STEMI & $1.30(0.67 ; 2.61)$ & 0.445 \\
NSTEMI & $0.97(0.45 ; 2.13)$ & 0.943 \\
\hline
\end{tabular}

OR: Odds Ratio; STEMI: acute myocardial infarction with ST-segment elevation (STEMI); NSTEMI: acute myocardial infarction without ST-segment elevation (NSTEMI)

between patients and healthcare staff at discharge and between the hospital and follow-up care. ${ }^{26}$

The present study showed that users of private health services showed higher odds of readmissions as compared with those attending public healthcare facilities. Also, the study showed an association between having access to private health services and the capacity of having health insurance. Thus, the type of health care is related to patients' socioeconomic status, race, educational attainment, family income and older age. ${ }^{27}$ In addition, the income may be associated with educational attainment, which indicates that people with higher education attainment have higher income and greater odds to have access to private health services. Therefore, users of health insurance plans have greater access to a high variety of health services, ${ }^{2,28}$ and an increase in the income is slightly associated with increasing acquisition of health insurance plans.

According to a Brazilian household budget survey (POF, Pesquisa de Orçamentos Familiares) conducted in 2008-2009, ${ }^{29}$ households spent an average of $5.9 \%$ of the family income with health care, including medications and health plans. ${ }^{27,29}$

A Brazilian nation-wide study by Malta et al. ${ }^{27}$ reported that in general, users of private health services are mostly women, white patients. Also, the use of health insurance plans is associated with socioeconomic status, reflected as race, educational attainment, family income and older age.

On the other hand, the public system is characterized by a difficult access to treatment, including invasive therapies such as myocardial reperfusion and medical treatment. Also, due to improvements in notification and classification of these events, complex cases are prioritized to hospitalizations. ${ }^{30,31}$ These findings corroborate previous results showing higher readmission rates in private health facilities than public ones.
The main reasons of readmission were cardiac conditions (53\%), mainly ACS, which accounted for $42.6 \%$ of the total. The high prevalence of cardiac causes of readmission was also reported by Khawaja et al. ${ }^{9}$ (69\%) evaluating 30-day readmission rates after percutaneous coronary intervention. Belitardo and Ayoub ${ }^{1}$ also found a higher frequency of ACS (41.6\%) among readmissions.

First hospitalization and readmission may occur for the same diagnosis due to the lack of resolution of the primary cause, which characterizes an avoidable readmission. ${ }^{1}$ Avoidable readmissions are considered those that are the result of a situation that if managed differently might have prevented the admission. ${ }^{32}$

These findings were similar to those reported by Ricci et al. ${ }^{8}$ showing a higher prevalence of cardiac causes of readmissions. Besides, increased risk of readmissions due to cardiac causes after the first ACS event has been reported. ${ }^{7}$ In the study by Kwok et al., ${ }^{33}$ although noncardiac causes were present in half of readmissions, cardiac causes were responsible for $46 \%$ of the cases, with chest pain of noncardiac origin and ACS the most prevalent diagnoses, respectively.

Different risk predictors of hospital readmission have been described in the literature. This may be explained by different characteristics of the study populations, including the presence of comorbidities, and particularities of health care centers.

Hospital readmissions may be related to several factors, such as patient's clinical condition, family and social support, and the quality of health care received during and after hospitalization. The high readmission rates draw attention to the need for the development of actions during hospitalization, at discharge, and during follow-up, considering patients' individual features, in order to reduce the number of readmissions. ${ }^{20,34}$ 
Our study has some limitations that should be considered. The lack of detailed information about the medications used by the patients and possible losses to follow-up. The readmissions were evaluated in the four main and referral cardiology hospitals of the city and therefore, a higher number of readmissions was somehow expected; we did not evaluate the occurrence of readmission in other hospitals in the city or in other cities. In addition, among these four institutions, there was only one public hospital, which requires referral for admission. These factors may have led to an underestimation of readmissions. On the other hand, this study design can be used to measure predictor variables before the occurrence of readmissions.

\section{Conclusion}

ACS was the main cause of readmissions within one year after the first admission, with higher prevalence among users of supplemental health care. The main determinants of readmission were the type of health care provided, and a previous diagnosis of congestive heart failure. The present study adds to the knowledge on determinants of readmission and may serve as a basis for implementation of assistance strategies that may reduce the occurrence of new admissions in medium- and long term, leading to better prognosis and lower costs to the health system.

\section{Author contributions}

Conception and design of the research: Oliveira LMSM, Costa IMNBC, Silva DG, Silva JRS, Buarque MDBM, Sousa ACS; Acquisition of data: Oliveira LMSM, Costa IMNBC, Buarque MDBM, Sousa ACS; Analysis and interpretation of

\section{References}

1. Belitardo JN, Ayoub AC. Identification of readmission predictors in elderly patients with acute coronary syndrome. Int J Cardiovasc Sci. 2015;28(2):139-47.

2. Louvison MC, Lebrão ML, Duarte YA, Santos JL, Malik AM, Almeida ES. Desigualdades no uso e acesso aos serviços de saúde entre idosos do município de São Paulo. Rev Saúde Pública. 2008;42(4):733-40.

3. McManus DD, Nguyen HL, Saczynski JS, Tisminetzky M, Bourell P, Goldberg RJ. Multiple cardiovascular comorbidities and acute myocardial infarction: Temporal trends (1990-2007) and impact on death rates at 30 days and 1 year. Clin Epidemiol. 2012;4(1):115-23.

4. Costa IM, Silva DG, Barreto-Filho JA, Oliveira JL, Silva JR, Buraque MD, et al. Diet quality of patients with acute coronary syndrome receiving public and private health care. Nutrition. 2019 Mar;59:131-7.

5. Panagiotakos DB, Notara V, Georgousopoulou EN, Pitsavos C, Antonoulas A, Kogias Y, et al. A comparative analysis of predictors for 1 - year recurrent acute coronary syndromes events, by age group: The Greek observational study of ACS (GREECS). Maturitas. 2015;80(2):205-11.

6. Steca P, Monzani1 D, Greco A, Franzelli C, Magrin ME, Miglioretti M, et al Stability and change of lifestyle profiles in cardiovascular patients after their first acute coronary event. PLoS One. 2017;12(8):e0183905

7. Southern DA, Ngo J, Martin BJ, Galbraith PD, Knudtson ML, Ghali WA, et al. Characterizing types of readmission after acute coronary syndrome hospitalization: implications for quality reporting. J Am Heart Assoc. 2014·3(5):e001046. the data: Oliveira LMSM, Costa IMNBC, Silva DG, Silva JRS, Barreto Filho JAS, Almeida-Santos MA, Oliveira JLM, Vieira DAS, Sousa ACS; Statistical analysis: Silva DG, Silva JRS, Vieira DAS; Writing of the manuscript: Oliveira LMSM, Costa IMNBC, Silva DG, Barreto Filho JAS, Almeida-Santos MA, Oliveira JLM, Vieira DAS, Sousa ACS; Critical revision of the manuscript for intellectual content: Oliveira LMSM, Silva DG, Barreto Filho JAS, Almeida-Santos MA, Oliveira JLM, Vieira DAS, Sousa ACS.

\section{Potential Conflict of Interest}

No potential conflict of interest relevant to this article was reported.

\section{Sources of Funding}

There were no external funding sources for this study.

\section{Study Association}

This article is part of the thesis of master submitted by Larissa Marina Santana, from Universidade Federal de Sergipe.

\section{Ethics approval and consent to participate}

This study was approved by the Ethics Committee of the Universidade Federal de Sergipe under the protocol number 2.203.855 / 302.544. All the procedures in this study were in accordance with the 1975 Helsinki Declaration, updated in 2013. Informed consent was obtained from all participants included in the study.

8. Ricci H, De Araújo MN, Simonetti SH. Readmissão precoce em hospital público de alta complexidade em cardiologia. Rev Rene. $2016 ; 17(6): 828-34$.

9. Khawaja FJ, Shah ND, Lennon RJ, Lusser JP, Alkatib AA, Rihal CS, et al. Factor associated with 30-day readmission rates after percutaneous coronary intervention. Arch Intern Med. 2012;172(2):112-7.

10. World Health Organization.(WHO). Diet, nutrition and the prevention of chronic diseases. Geneva;1990. ( Report of a WHO group. Technical Report Series. No 797)

11. Lebrão ML, Duarte YAO (orgs). SABE - Saúde, Bem-estar e Envelhecimento O Projeto Sabe no município de São Paulo: uma abordagem inicial. Brasília: Organização PanAmericana da Saúde (OPAS); 2003.

12. Matsudo S, Araújo T, Matsudo V, Andrade D, Andrade E, Oliveira L, et al Questionário Internacional de Atividade Física (IPAQ): estudo de validade e reprodutibilidade no Brasil. Rev Bras de Ativ Fís Saúde. 2001;6(2):5-12.

13. IPAQ Research Committee. Guidelines for the data processing and analysis of the International Physical Activity Questionnaire. No. 2005.[Cited in 2018 Ju 12]. Available from: http://www.ipaq.ki.se/scoring.pdf.

14. R Core Team (2016) R: A Language and Environment for Statistical Computing. R Foundation for Statistical Computing. Vienna, Austria.

15. Dreyer RP, Dharmarajan K, Kennedy KF, Jones PG, Vaccarino V, Murugiah K, et al. Sex Differences in 1-Year All-Cause rehospitalization in patients after acute myocardial infarction. Circulation. 2017;135(6):521-53. 


\section{Original Article}

16. Sangu PV, Ranasinghe I, Aliprandi Costa BA, Devlin G, Elliot J, Lefkovitz, et al. Trends and predictors of rehospitalisation following an acute coronary syndrome: report from the Australian and NewZealand population of the Global Registry of Acute Coronary Events (GRACE). Heart. 2012;98(23):1728-31.

17. Gheorghiade $M$, Vaduganathan $M$, Fonarow GC, Bonow RO. Rehospitalization for Heart Failure. J Am Coll Cardiol. 2013:61 (4):391-403.

18. Reis MB, Dias MG, Bibanco MS, Lopes CT, Gea NG. Readmissão hospitalar por insuficiência cardíaca em um hospital de ensino. Medicina (Ribeirão Preto). 2015;48(2):138-42.

19. Mendes EV. As redes de atenção à saúde. Cien Saude Colet. 2010;15(5):2297-305.

20. Sousa FOS, De Medeiros KR, Gurgel Júnior GD, De Albuquerque PC. Do normativoà realidade do Sistema Único de Saúde: revelando barreiras de acesso na rede de cuidados assistenciais. Cien Saude Colet. 2014; 19(4):1283-93.

21. Fischer C, Steyerberg EW, Fonarow GC, Ganiats TG, Lingsma HF. A systematic review and meta-analysis on the association between quality of hospital care and readmission rates in patients with heartfailure. Am HeartJ. 2015;170(5): 1005-17.

22. Ziaeiana B, Fonarowc GC. The prevention of hospital readmissions in heart failure. Prog Cardiovasc Dis. 2016;58(4):379-85.

23. Barreiros BRN, Bianchi ERF, Turrini RNT, Poveda VB. Causas de readmissão hospitalar após cirurgia cardíaca. Rev Eletr Enf. 2016;18:e1182

24. Mirkin KA, Enomoto LM, Caputo GM, Hollenbeak CS. Risk factors for 30-day readmission in patients with congestive heart failure. Heart Lung. 2017;46(5):357-62.

25. Van Walraven C, Jennings A, Forster AJ. A meta-analysis of hospital 30-day avoidable readmission rates. J Eval Clin Pract. 2012;18(6):1211-8.
26. Bradley EH, Curry L, Horwitz LI, Sipsma H, Wang Y, Walsh MN, et al. Hospital strategies associated with 30-day readmission rates for patients with heart failure. Circ Cardiovasc Qual Outcomes. 2013;6(4):444-50.

27. Malta DC. Stopa SR, Pereira CA, Szwarcwald CL, Oliveira M, Reis AC. Cobertura de planos de saúde na população brasileira, segundo a Pesquisa Nacional de Saúde, 2013. Cien Saude Colet. 2017;22(1):179-90.

28. Malta DC, Bernal RTI. Comparação dos fatores de risco e proteção de doenças crônicas na população com e sem planos de saúde nas capitais brasileiras, 2011. Rev Bras Epidemiol. 2014;17(1):241-55.

29. Instituto Brasileiro De Geografia e Estatística (IBGE). Pesquisa de orçamentos familiares 2008-2009. Perfil das despesas no Brasil - indicadores selecionados. Brasília;2012.

30. Sociedade Brasileira de Cardiologia. IV Guidelines of Sociedade Brasileira de Cardiologia for treatment of acute myocardial infarction with STsegment elevation. Arq Bras Cardiol. 2009;93(6 Suppl 2):e179-264. Erratum in: Arq Bras Cardiol. 2010;95(4):553.

31. Sociedade Brasileira de Cardiologia. Diretriz de telecardiologia no cuidado de pacientes com síndrome coronariana aguda e outras doenças cardíacas. Arq Bras Cardiol. 2015;104(5 Suppl 1):1-26.

32. Redfern J, Hyun K, Santo K. Challenges and opportunities associated with quantification of cardiovascular readmissions. J Am Heart Assoc. 2014;3(5):1-3.

33. Kwok HS, Wonga CW, Shufflebotham H, Brindley L, Fatima T, Shufflebotham A, et al. Early readmissions after acute myocardial infarction. Am J Cardiol. 2017;120(5):723-8.

34. Barekatain M, Maracy MR, Hassannejad R, Hosseini R. Factors associated with readmission of patients at a university hospital psychiatric Ward in Iran. Psychiatry J. 2013;2013:685625. 